DOI 10.20396/temáticas.v20i40.11427

\title{
A PRÁTICA DO SWING E A DIMENSÃO DO PRAZER
}

\author{
Olivia Von Der Weid*
}

\begin{abstract}
RESUMO: O objetivo deste artigo é refletir sobre questões referentes às relações afetivo sexuais entre homens e mulheres na sociedade atual a partir da experiência de casais adeptos da prática do swing. Particularmente, procuro compreender quais dimensões da experiência estariam envolvidas no discurso dos adeptos do swing sobre o prazer que obtém em sua prática. Busco analisar os diferentes aspectos que parecem relacionados ao se falar em prazer para os adeptos da troca de casais: a fantasia, a transgressão, a intensidade e o controle. Qual o sentido que os casais entrevistados dão para a sua experiência? Até onde vai a busca pela satisfação de fantasias sexuais? Há um limite para a intensificação do prazer? A reflexão está baseada na análise de 13 entrevistas realizadas com casais adeptos da prática do swing entre os anos de 2003 e 2007 na cidade do Rio de Janeiro. Também são fontes de análise as anotações resultantes de observação participante realizada em dezenove encontros semanais de casais praticantes de swing, em uma casa especializada na Zona Sul carioca e outra no Centro.
\end{abstract}

PALAVRAS-CHAVE: Gênero, sexualidade, corpo, casamento, infidelidade, prazer, troca de casais.

\footnotetext{
* Mestre em Sociologia (com concentração em Antropologia) pelo programa de Pós-Graduação em Sociologia e Antropologia (PPGSA) da UFRJ. E-mail: oliviaweid@gmail.com.
} 


\section{INTRODUÇÃO}

Entre 2003 e 2008 desenvolvi uma pesquisa sobre a prática do swing entre casais habitantes da cidade do Rio de Janeiro. A pesquisa teve por objetivo discutir questões referentes às relações afetivo-sexuais entre homens e mulheres na sociedade atual a partir da experiência de casais adeptos da prática do swing, e resultou na dissertação "Adultério Consentido: corpo, gênero e sexualidade na prática do swing". Procurei compreender principalmente as concepções nativas sobre casamento, sexualidade, infidelidade e, também, as regras de uma relação "swinger", destacando as diferenças de gênero existentes.

Neste artigo pretendo realizar uma reflexão mais aprofundada sobre a noção de prazer envolvida na prática do swing. Procuro compreender o discurso dos adeptos do swing sobre o prazer que obtém em sua prática. Busco analisar os diferentes aspectos que parecem relacionados ao se falar em prazer para os adeptos da troca de casais: a fantasia, a transgressão, a intensidade e o controle. Qual o sentido que os casais entrevistados dão para a sua experiência? Até onde vai a busca pela satisfação de fantasias sexuais? Há um limite para a intensificação do prazer? Faço também uma reflexão sobre as relações de amizade entre os casais entrevistados e da importância que este vínculo adquire no universo pesquisado.

Esta reflexão está baseada na análise de 13 entrevistas realizadas com casais adeptos da prática do swing entre os anos de 2003 e 2007 na cidade do Rio de Janeiro. Também são fontes de análise as anotações resultantes de observação realizada ao longo do mesmo período em dezenove encontros semanais de casais praticantes de swing, em uma casa especializada na Zona Sul carioca e outra no Centro. Material de mídia impressa e virtual (Internet) também são fontes de pesquisa.

Um estudo sobre a prática da troca de casais é uma tentativa de 
compreender as mudanças e permanências nas representações de gênero e nos ideais de conjugalidade presentes na cultura atual. Busco entender os "novos arranjos conjugais" que podem ser verificados em nossa sociedade, procurando pensar de que maneira essa forma de relacionamento contribui para uma discussão mais ampla sobre casamento, prazer e sexualidade nas relações afetivo-sexuais contemporâneas.

\section{FANTASIA E TRANSGRESSÃO}

"O swing é um mundo onde você pode tudo, mas não é obrigado a nada" depoimento de um entrevistado

Através das leituras de reportagens e de sites, e das informações que obtive no trabalho de campo, pude perceber que outros comportamentos sexuais, além da troca de casais propriamente dita, são encontrados no meio swinger. Existem diferentes tipos de casais que freqüentam este meio, com interesses variados. Alguns são adeptos do voyeurismo, outros do exibicionismo. O ménage feminino (duas mulheres e um homem) e o ménage masculino (dois homens e uma mulher) também são comportamentos comuns.

Tem vários tipos de casais, tem casais que gostam só de ver, tem casais que não aceitam a troca, tem casais que só aceitam fazer no mesmo cômodo com outro casal, mas que não gostam nem que encoste, tem casais que só gostam que encoste, mas nada mais do que isso... (Ana).

Parker (1991) chama atenção para a fantasia, construída com pensamentos e imagens, como expressão ideal da lógica cultural que organiza o erótico. Segundo o autor, como todo o imaginário erótico, o enfoque da fantasia será a satisfação dos desejos. Sobre essa questão, é interessante o que um entrevistado disse a respeito do swing:

Temáticas, Campinas, 20(40): PG-PG, ago./dez. 2012 


\begin{abstract}
Na verdade é uma fantasia nossa, nós não estamos atrás de outros relacionamentos, nós estamos atrás de fantasia. Então na verdade o que a gente vem buscar aqui são personagens dessa fantasia, pode ser qualquer personagem. Dentro desses personagens você idealiza algumas coisas, já que é uma fantasia e você está liberado para fantasiar, para sonhar, então você também tem todo o direito de selecionar, não quero esse personagem com esse biotipo, eu quero um outro, com outro tipo, então é por aí. (Felipe).
\end{abstract}

Nem todos os casais têm o mesmo perfil quando se trata de realizar fantasias sexuais. Em sua entrevista, André indica que existem casais que se satisfazem com o swing ou com alguma fantasia específica, mas que, para outros, a fantasia já realizada deixa de ser estimulante após algum tempo e busca-se, então, a realização de novas fantasias, em um jogo onde vai se ampliando o limite da transgressão. De acordo com Campbell (1995), um determinado estímulo, se não se transforma, rapidamente deixa de ser estimulante e, como conseqüência, perde a sua possibilidade de gerar prazer. Nesse sentido, a capacidade de se experimentar prazer repetidamente com sensações derivadas de uma certa atividade será ameaçada caso haja uma exposição excessivamente freqüente a ela ou excessivamente longa. É interessante como esta idéia do autor aparece exemplificada nas palavras de André:

Existem dois grupos de swingueiros. Tem os swingueiros convictos e que não têm expectativa de nada fora do swing. Vão ser sempre swingueiros. Eu conheço casais que fazem swing há 20 anos e são felizes da vida. Agora da grande maioria que eu conheci, o swing, ele é assim, é um estágio da vida do casal. Ele começa como um alimento, como um ingrediente, como um aditivo, passa a ser parte da rotina e depois desaparece, porque cai na mesmice, é aquele mais do mesmo. (André)

Temáticas, Campinas, 20(40): PG-PG, ago./dez. 2012 
A reflexão de Campbell sobre o hedonismo moderno se mostra essencial para se compreender esta busca por prazer entre os praticantes de swing, a elaboração constante de novas fantasias e a sensação inevitável de insatisfação que aparece em seus discursos. Segundo Campbell, um dos aspectos fundamentais que caracterizam o hedonismo moderno seria a fantasia ou devaneio. Para o autor, o próprio desejo se torna uma atividade prazerosa. Querer, ao invés de ter, se torna o foco principal de quem procura o prazer. O dilema aparece na constatação de que os prazeres atuais provindos de uma experiência real não são comparáveis àqueles que se encontram na imaginação. Não necessariamente por uma questão do impacto da realização, mas sim pela perfeição que a fantasia adquire na imaginação, mas que dificilmente pode adquirir quando consumada na realidade. A consumação do desejo, nesse sentido, será necessariamente uma experiência de desilusão, a fantasia perfeita em contraste com a realidade, o que tem como resultado o reconhecimento de que algo se perdeu.

A busca pelo swing é justificada pelos entrevistados como uma procura por aumentar o prazer e por satisfazer as fantasias sexuais do casal. Após três anos do início da pesquisa, voltei a entrevistar um dos casais, que se separou, e pude perceber a concretização, no que diz respeito à sexualidade, do ciclo de desejo-aquisição-uso- desilusão-renovação-desejo, descrito por Campbell. André descreveu da seguinte forma o seu cansaço em relação às festas de swing:

Com relação às festas, por exemplo, chegou uma hora que aquele ambiente cansou para nós. Esgotou. A gente não estava tendo mais nenhum prazer em participar daquelas festas naquele molde. Era sempre mais do mesmo. Eu sempre gostei de coisa nova, de novidade, e ela também, então a gente começou a ir, virou monotemático demais. A gente ia sempre e via as mesmas pessoas, falava as mesmas coisas, era novidade para os outros, mas para a gente não era mais. Pra mim, eu que montei a festa, montei a estrutura, que criei aquela coisa toda, começou a ficar chato, porque eu estava me repetindo. (André) 
Um dos resultados deste ciclo descrito por Campbell parece ser o de que o prazer acaba exigindo doses cada vez maiores. Neste ponto cabe lembrar Simmel (2005) que, ao descrever o comportamento dos habitantes das grandes cidades, destaca a indiferença como uma consequência da atitude blasé, uma defesa contra os excessos de estímulos e a velocidade dos acontecimentos na metrópole. No discurso do entrevistado, pode-se perceber este relativo anestesiamento e a sensação de ansiedade e insatisfação permanentes.

Fizemos uma viagem para Camboriú e fomos a dois clubes de swing lá. Exatamente a mesma coisa que a gente estava vendo aqui, de você não conseguir se excitar com o ambiente mais. Falta novidade. Eu acho que o swing, para a grande maioria das pessoas, ele é uma grande novidade durante um tempo. Eu me lembro da primeira vez que eu fui a um clube, eu olhava aquelas coisas e me excitava só em ver. Eu sentava do lado do casal que estava se tocando e ficava de pau duro. E depois com o tempo ficou banal demais. Essa coisa pra nós ficou muito costume. Então, por exemplo, eu estava numa festa com um monte de gente pelada, a maioria das pessoas transando e eu não tinha o menor tesão, não conseguia me excitar. E ela também não. Então a gente falou "pô, não dá pra fazer por fazer". A gente montava a festa, organizava, todo mundo transava e a gente não. (André).

Campbell indica que, após a sensação de frustração advinda da concretização da fantasia, o devaneio será levado adiante e será associado a um novo objeto de desejo de forma que os prazeres ilusórios possam ser, mais uma vez, re-experimentados. A alternativa adotada pelo casal entrevistado foi justamente a de recorrer à imaginação para criar novas fantasias.

Mesmo não me excitando ir nas festas, eu continuei liberal e querendo, aí nós começamos a procurar outras formas pra nos excitar. Então a gente começou a fazer uma coisa canalha, mas que era o que dava tesão... liga pro cara e propõe sair com ele dizendo que eu não sabia, pra ver se ele 
topa. E o cara topou. E ela começou a sair com ele, ele achando que eu não sabia, mas eu sabia. Quer dizer o pato na história era ele. Ele achava que estava saindo com ela e me traindo e não, a gente combinava, ela botava o celular pra eu ouvir, aquela história toda, e isso começou a dar tesão. (André)

Para Campbell, as combinações possíveis da fantasia são ilimitadas, mas a chave para a sua elaboração se encontra na lógica da transgressão. Duarte (2004) também enfatiza o aspecto da transgressão na obtenção do prazer nas sociedades contemporâneas. No swing, a fantasia é construída não só com pensamentos e imagens, mas envolve a dimensão da vivência. Sair da esfera do imaginário e entrar no mundo da experiência parece resultar, para os pesquisados, em uma constante elaboração de novas fantasias e, conseqüentemente, novas transgressões.

Um dos aposentos que invariavelmente está presente nas casas de swing é o chamado "quarto coletivo". Gostaria de fazer uma analogia entre o quarto coletivo e o boudoir, descrito por Moraes (1994), destacando as semelhanças e diferenças entre praticantes de swing e libertinos.

Moraes (1994) descreve o boudoir como a unidade mínima do espaço sadiano, de concentração da luxúria e síntese da libertinagem, local de excessos, onde acontecem as orgias, flagelações, assassinatos, todas as volúpias. O boudoir representaria o interstício entre o social e o pessoal, onde os novos regimes dos prazeres e das satisfações são testados. Seria um pequeno aposento, onde os devassos encontrariam a privacidade para realizar a intimidade libertina.

Em uma casa de swing existem outros espaços além do quarto coletivo. Comparável ao banquete na sociedade setencentista, a boate pode ser descrita como o lugar da sociabilidade, onde, ainda vestidos, os casais se encontram, se conhecem, conversam, dançam, comem e bebem. As mesas em geral circundam o espaço de maneira a facilitar o contato entre os casais, todos podem ver e serem vistos. Além da boate existem os quartos individuais, que possuem portas com trancas, onde dois casais (ou mesmo apenas um) podem entrar e se isolar na intimidade das quatro paredes, um local privado. Já o quarto coletivo é o lugar das "surubas", onde muitos casais e solteiros (nos 
dias em que a casa permite sua entrada), interagem sexualmente. $O$ espaço da "sacanagem", onde tudo é permitido, nada é obrigatório. A mesma economia de objetos apontada por Moraes (1994) no boudoir pode ser encontrada ali. Ao invés da otomana, a cama king size, os espelhos que circundam o ambiente e a não obrigação da presença de todos.

Moraes (1994) aponta a apatia como o princípio fundamental da libertinagem. Envolvendo as noções de distância, deslocamento e afastamento, é somente através da apatia que seria possível chegar ao absoluto prazer. Ela permite isolar as experiências sensíveis das convenções morais, dando lugar à sensibilidade superior do crime. Esta indiferença e desligamento das exigências da vida em sociedade são condições espirituais necessárias para o alcance da felicidade, que, para os libertinos, é temporal, material e corporal, está ligada à noção de intensidade.

No swing, as práticas sexuais realizadas em um quarto coletivo não se parecem com as de um boudoir, onde eram cometidos assassinatos, incestos, mortes lentas, com o fim de aumentar a sensibilidade dos órgãos e incrementar os prazeres da libertinagem. Entretanto, se traduzirmos para um contexto contemporâneo, percebe-se que é também necessário um certo grau de distanciamento das convenções morais em um quarto coletivo. Ali homens e mulheres assistem seus parceiros se relacionando com outra pessoa, as mulheres fazem sexo com vários homens e com várias mulheres, ao mesmo tempo ou em série. Um lugar onde são praticados os "vícios privados", inaceitáveis socialmente.

Há, entretanto, um aspecto fundamental que diferencia o boudoir de um quarto coletivo. O desligamento do boudoir se dá através da completa separação entre indivíduo e sociedade, onde o objetivo último é a felicidade. No quarto coletivo, o distanciamento se expressa através da separação entre amor e sexo, com o objetivo último do prazer, mas o desligamento em relação à sociedade não é completo, uma vez que se mantém o vínculo matrimonial.

A diferença fundamental e possível contradição dos casais swingers é justamente a de querer realizar esta busca pelo prazer e satisfação enquanto casal, não só preservando, mas também valorizando o vínculo do casamento. A experiência swinger não é radical como a libertina, pois não segue os desejos 
até as últimas consequências. O casal é o limite e a experiência do prazer é vivida somente se permitida pelo(a) parceiro(a). Quando analisamos a prática do swing, é possível perceber com nitidez a tensão que aparece entre libertinagem e limites. Por meio do consenso, o swing adquire uma legitimidade que o torna possível e é essa consensualidade do casal e entre casais que permite controlar a radicalidade da busca pelo desejo até as últimas conseqüências, que está presente no boudoir.

\section{O SWING E O MUNDO LIBERAL}

Os casais que procuram uma casa de swing não parecem apresentar os mesmos desejos e fantasias e nem todos são adeptos das mesmas práticas sexuais.

Conceitualmente o swing é a troca de casais, se você pegar ao pé da letra é a troca de casais. Só que hoje é muito difícil um casal, até tem, mas o casal não faz só swing, ele faz swing, ele faz ménage, faz um ménage com homem, ménage com uma mulher. (Ana).

Respeitar a vontade do outro, no próprio relacionamento com o parceiro e na relação com os outros casais aparece como um dos princípios mais citados pelos entrevistados como fundamentais no meio swing. Um entrevistado afirma: "o swing tem esse código de ética forte, o respeito né, o respeito não só entre eu e ela, mas o respeito entre nós e o resto, e a comunidade" (Emanuel).

Uma das principais idéias que ouvi ao longo da pesquisa de campo foi que o swing é um mundo onde "você pode tudo, mas não é obrigado a nada". Não apenas no "tudo" desta frase, mas também no comportamento dos casais e em suas concepções do erótico, o swing parece se aproximar daquilo que Parker (1991) descreve como sacanagem. Um mundo onde são permitidas as práticas que excedem o limite do bom gosto, descritas pelo autor, e que justamente por isso são vistas como especialmente excitantes.

Temáticas, Campinas, 20(40): PG-PG, ago./dez. 2012 
Uma matéria da revista Marie Claire ${ }^{1}$ serve como exemplo da diversidade de práticas que são realizadas em casas de swing: "sob a etiqueta 'swing', além da literal troca de casais, existem práticas diversas: voyeurismo, sexo a três, homossexualidade feminina e sexo grupal". Nem todos os casais aderem, na prática, à troca de parceiros. Existem aqueles que preferem só olhar, outros que trocam carícias, mas só se relacionam sexualmente com seu parceiro, os que só gostam de serem vistos e ainda aqueles que realmente são adeptos da troca e de outras práticas.

Ao mesmo tempo, a esfera pública estaria protegida pelo anonimato da prática. Os adeptos do swing são pessoas que prezam pela preservação de suas identidades através do uso de apelidos e do completo sigilo a respeito de seu comportamento para outras pessoas que não as que também são praticantes. Para os praticantes de swing, o aspecto do sigilo e do risco de ser "descoberto" também torna a prática mais excitante.

No ambiente swing muitas práticas consideradas proibidas são vistas como positivas e as transgressões incluem a presença de outras pessoas, expressando-se em práticas como assistir o parceiro se relacionando sexualmente com outra pessoa, sexo no mesmo ambiente com outros casais, a própria troca de parceiros, o ménage feminino ou masculino, o chamado gang-bang ${ }^{2}$, entre outras.

Butler (2003) afirma que a heterossexualidade é percebida como um sistema total e é justamente essa percepção que afasta as possibilidades de resignificação dessa heterossexualidade. Para a autora, mesmo que a heterossexualidade apareça como obrigatória ou presumida, não decorre daí que todos os atos heterossexuais sejam radicalmente determinados. Mesmo não contestando a forma principal e legítima de relacionamento na sociedade - o casamento heterossexual - a prática do swing traz à tona a problemática de como gerir o desejo dentro dessa norma compulsória de relação afetivosexual.

Rubin (1984) demonstrou que na sociedade ocidental moderna os atos, as práticas e as escolhas sexuais se dão no interior de um sistema hierárquico

\footnotetext{
${ }^{1}$ Marie Claire, novembro de 2002, edição 140.

${ }^{2}$ Quando a mulher tem relações sexuais em série com vários homens, um atrás do outro.

Temáticas, Campinas, 20(40): PG-PG, ago./dez. 2012
} 
de valorização sexual, onde a sexualidade considerada normal é a que se realiza por meio de relações heterossexuais firmadas no matrimônio, com fins reprodutivos. A autora levanta uma série de outras situações em escala de valorização decrescente, onde os casais gays e lésbicas estariam situados mais abaixo e, portanto, sofreriam uma desvalorização social. Acredito que o estudo da prática do swing revela que as relações heterossexuais fundadas no matrimônio não podem ser vistas como um conjunto homogêneo. A heterossexualidade que encontrei entre casais praticantes de swing envolve uma série de práticas erótico-afetivas, incluindo práticas homossexuais entre mulheres ${ }^{3}$, que permitem problematizar este modelo de oposição hetero versus homo como categorias fixas e excludentes, demonstrando não existir uma única forma de se viver a heterossexualidade.

Outro ponto que merece atenção diz respeito a uma idéia que está muito presente no meio: a de um mundo liberal. Fui percebendo, ao longo da pesquisa, que o swing estaria englobado por uma espécie de mundo maior que seria este "mundo liberal". Nem todos os adeptos do swing fariam parte deste mundo, que inclui práticas sexuais que podem ir muito além da troca de casais propriamente dita. Neste mundo liberal estariam incluídas a realização de fantasias específicas, como, por exemplo, a da mulher sair sozinha com outro homem para depois contar para o marido. Expressões como "vida liberal", "essência liberal", "potencial liberal", "perfil liberal", "ambiente liberal" são recorrentes nas entrevistas.

Na verdade o liberal, a idéia que se tem de liberal, são pessoas que tem uma vida sexualmente liberal, pode ser menáge, pode ser swing, pode ser suruba, pode ser de ir lá só para assistir. Se você for pegar na raiz mesmo, swing, é aquela pessoa que faz troca de casais, só que a coisa não é tão simples assim, você pode cair no meio de uma suruba, você pode ir e só ficar olhando e não fazer nada e ser considerado um casal liberal. Entendeu? Para mim um casal liberal é um

\footnotetext{
${ }^{3}$ Para uma discussão mais aprofundada sobre as práticas homossexuais encontradas no meio swinger e sua relação com a identidade de gênero ver von der Weid, 2009.
} 
casal que se permite sexualmente tudo e que não fica encanando do outro estar fazendo alguma coisa. (Ana)

A idéia de uma "vida sexual liberal" presente nas entrevistas pode ser pensada a partir do que Gregori (2004) coloca sobre o surgimento de um "erotismo politicamente correto". A autora identifica, em pesquisa realizada em sex-shops de São Francisco, um movimento de deslocamento do significado de transgressão do erotismo para uma definição relacionada ao cuidado saudável do corpo e fortalecimento do self. O sentido de tal erotismo seria o de transgredir restrições ao livre exercício da sexualidade. Gregori aponta ainda para uma dimensão de domesticação dos traços e conteúdos violentos neste erotismo politicamente correto, a qual farei referência mais adiante

Os manuais encontrados por Gregori nos sex-shops (para uso de sex-toys e práticas $\mathrm{S} / \mathrm{M}^{4}$ ) procuram tornar legítima a prática em questão. Segundo a autora tais manuais

buscam desinvestir o caráter transgressor dos exercícios, descaracterizar o caráter o patológico e perverso dos agentes envolvidos e convidar os leitores a experimentarem essas formas de sexualidade. Todos eles enfatizam como essa expansão das fronteiras eróticas reforça a auto-estima das pessoas, libertando-as de preconceitos e estimulando a imaginação. (2004:249)

O suposto mundo liberal a que se referem meus pesquisados seria composto por casais que procuram vivenciar este "erotismo politicamente correto", ampliando o escopo de práticas sexuais possíveis não apenas por meio do uso de acessórios disponíveis no mercado erótico, mas também pela vivência de situações sexuais que incluem a presença e a participação de outros indivíduos.

${ }^{4} \mathrm{~A}$ sigla $\mathrm{S} / \mathrm{M}$ se refere às chamadas práticas sadomasoquistas.

Temáticas, Campinas, 20(40): PG-PG, ago./dez. 2012 
Ser parte de um mundo liberal aparece nos discursos relacionado à vivência de fantasias sexuais, a uma experimentação sexual maior e, conseqüentemente maior liberdade e maior conhecimento de si. Ser parte deste mundo também pode ser vinculado a um mercado pornográfico, envolvendo a esfera do consumo. Freqüentar casas de swing, festas de fetiche, ou contratar serviços de prostituição, freqüentar a praia em local onde se reúnem casais adeptos do swing, homossexuais e simpatizantes, seriam alguns exemplos. Fazer uso de produtos de sex-shops, visitar sites da internet, também estariam inseridos nesta esfera. $\mathrm{O}$ sexo não se restringe mais ao âmbito das quatro paredes, se espalha por um ambiente mais amplo, mas que de qualquer maneira ainda pode conter uma dimensão de controle por meio do anonimato.

A mesma pesquisada mencionada acima indica que nem todos que praticam swing poderiam ser considerados parte deste mundo liberal. Ser liberal seria algo temporário para algumas pessoas, uma fase da vida, enquanto que, para outras, seria algo definitivo, da personalidade do indivíduo.

Eu acho que eu não tenho uma essência liberal, eu passei por uma fase liberal entre aspas, e agora eu não estou mais. No caso do Andre (ex marido da entrevistada) ele sempre teve uma vida que não foi liberal e aí a gente teve uma vida liberal e ele está continuando, porque? Porque a essência dele é liberal. Eu acho que é importante você saber o que você quer para você. (Ana)

Foucault (2005) demonstrou que não apenas o sexo, mas também o discurso sobre o sexo, se transformaram em uma fonte de acesso à inteligibilidade individual, à totalidade do corpo ou à própria individualidade no dispositivo da sexualidade. Na sociedade ocidental moderna, de acordo com o autor, a construção da pessoa passa pela emergência da sexualidade enquanto novo locus de verdade do sujeito. O sexo é colocado em discurso e se transforma naquilo que tem o poder de dizer a verdade sobre o indivíduo. Por meio do discurso sobre o sexo, desenvolve-se um saber sobre o sujeito. O depoimento desta entrevistada sugere que ser liberal, temporária ou 
"essencialmente", possibilitaria um maior conhecimento de si a partir de experiências que envolvem práticas sexuais. "Saber o que se quer para você" aparece relacionado às experiências sexuais de sua vida, que definem aquilo que se é - liberal por essência, fase da vida liberal - tendo conseqüências em sua trajetória - continuar uma vida liberal ou interrompê-la. No caso da entrevistada, como ela sugere, o marido continuou e ela própria interrompeu, o que teve como conseqüência o fim de seu casamento.

Outro aspecto interessante que pode ser observado na prática do swing resulta de uma combinação de duas idéias: anonimato e personagem. Tornar-se adepto de uma prática onde uma das maiores preocupações é a preservação da identidade implica a adoção de apelidos ou nomes fictícios por parte dos praticantes. Esse ingrediente, o anonimato, permitiria uma maior liberdade para a realização de fantasias específicas do casal, que pode brincar com a noção de identidade adotando uma personagem naquele meio.

Ana: as pessoas acreditavam num personagem que a gente criou, do marido e da esposa, acreditavam naquele personagem e a gente vivia aqueles personagens na frente das pessoas e quando a gente não estava ali a nossa vida era completamente diferente.

Pergunta: As pessoas criam personagens para si mesmas quando estão lá?

Ana: acho que cria... primeiro que você já troca de nome, concorda? Você não é a Olivia, você passa a ser a Joana. Aí se você já não usa o seu nome, você já está tirando uma parte sua, você está usando um pedaço seu. Não estou falando que esse personagem não tenha coisas suas, mas não é você. Aí você pode ser o que você quiser.

Dessa maneira, a proteção do anonimato permite um jogo de reinvenção que permite que a fantasia se torne realidade, na tentativa de criar um mundo onde os mais diferentes desejos possam ser satisfeitos. 


\section{INTENSIDADE E CONTROLE}

Um aspecto possível de ser observado na prática do swing, e que diz respeito à concepção sobre o prazer, é a importância da intensidade da experiência. Esta intensidade está diretamente relacionada aos corpos no sentido de experimentação, de ir até ou além do limite. Nem todos os casais apresentam este tipo de comportamento, mas ele está presente na prática do gang-bang, por exemplo, quando uma mulher tem relações em série com vários homens, um depois do outro. Uma analogia com o uso das drogas e seus efeitos pode ser interessante para compreender esta dimensão do prazer.

Vargas (1998), em seu estudo sobre o consumo de drogas legais e ilegais, revela um processo de "analgesia coletiva" na sociedade contemporânea. O autor enfatiza que o ideal médico do "bem estar", ao lado da luta contra a morte e pela cura das doenças, demanda uma luta pela eliminação da dor e do sofrimento. No processo de medicalização da dor, o próprio corpo deve se calar e, paralelamente a uma incitação ao consumo medicamentoso de drogas legais, os limiares de suportabilidade do sofrimento são reduzidos drasticamente, tendendo-se à supressão da própria experiência da dor. Neste processo de "analgesia coletiva", a saúde é reduzida à insconsciência do próprio corpo, uma espécie de anestesiamento.

Vargas aponta que em "sociedades analgésicas" há um aumento da demanda por estímulos cada vez mais poderosos para as pessoas terem a impressão de que estão vivas. $\mathrm{O}$ autor argumenta que a experiência do consumo não medicamentoso de drogas coloca em jogo modos intensivos de produção dos corpos, onde o vigor do instante da vida se impõe sobre a duração da vida em extensão. Acredito que algumas práticas observáveis no meio swing têm por característica este uso intensivo dos corpos, não pelo consumo de drogas, mas através de uma certa "experimentação sexual". O relato de uma entrevistada, expressa o aspecto da intensidade do uso dos corpos que procuro destacar aqui:

Já aconteceu de eu chegar num clube e dar para 8 homens. Porque naquela noite eu estava com muita vontade de fazer 
sexo, mas eu não queria fazer sexo com o meu marido, eu tava a fim de fazer sexo com outros homens, eu queria conhecer vários homens. Realmente eu dei para 8 homens e depois eu fiquei assim "meu Deus, como eu consegui", mas eu precisava me experimentar, eu precisava saber o meu limite, ver até aonde eu poderia ir. (Irene)

A comparação com o uso de drogas aparece na entrevista de um dos casais em torno da idéia de vício. A freqüência a uma casa de swing, de acordo com eles, pode se tornar um vício. Tornar-se "viciado", no depoimento do casal, aparece muito mais como uma característica masculina do que feminina. À mulher caberia o papel de manter o equilíbrio do casal, apontando os momentos em que se tornaria necessário um afastamento do meio (ou do vício).

Henrique: a gente às vezes até tem que viajar um pouco, para sair desse vício, porque isso é uma cocaína.

Pergunta: você acha que se torna um vício?

Henrique: ah torna. Se ela não fosse o meu grande freio, eu era muito mais viciado nisso.

Pergunta: mas vicia em que sentido?

Henrique: porque de repente aquilo deixa de ser o tempero e você quer aquilo como o teu prato diário, e aquilo tem que ser o tempero.

Heloísa: tem que ser que nem uma pimentinha, que se botar demais vai estragar.

Henrique: aí ela é o meu ponto de equilíbrio disso, ela diz não, está demais. Muda, isso muda o nosso relacionamento. Mas o legal é quando a gente viaja, até mesmo passar o final de semana no Recreio, a gente não entra em contato com o meio, a coisa volta a fluir mais normalmente. Sem dúvida nenhuma isso muda, você cria uma certa dependência da coisa, eu sinto isso. É errado? É errado, mas é uma cocaína. Porque a cocaína ela te dá uma dependência química, e isso é quase que uma dependência química, é a tua química 
mesmo né, porque a gente é tudo química, tudo é hormônio, glândulas. ${ }^{5}$

Este depoimento também chama a atenção para uma dimensão que aparece relacionada ao prazer para estes casais: a do swing como uma experiência intensa para os sentidos. Em uma casa de swing, especialmente em certos aposentos como o quarto coletivo ou o labirinto ${ }^{6}$, diversos estímulos ocorrem concomitantemente, podendo afetar os cinco sentidos: olfato, tato, visão, audição e paladar.

Na prática do swing o olhar é a experiência que mais se destaca, e a figura do voyeur é muito comum. De acordo com uma pesquisada, a maioria dos casais que vai a casas de swing não chegam a realizar a troca, vai somente para olhar.

No swing o prazer voyeur aparece explicitamente no comportamento dos casais que freqüentam uma casa apenas para olhar, mas também inclui o prazer de ser visto. $\mathrm{O}$ exibicionismo e o voyeurismo são práticas que se complementam e influenciam o comportamento dos casais. De acordo com uma entrevistada:

Você vê que as mulheres quando transam fazem muita mise-en-scène, sabe? Se eu vou dar um gemido, o meu gemido é mais alto, se eu vou transar, eu vou ter uma performance, eu vou caprichar mais. Eu mesma já fiz isso várias vezes, não vou dizer pra você que não fiz. Claro, porque você está ali em um ambiente que está todo mundo te vendo, que você está se expondo, que você está se exibindo, que você está se mostrando pra um outro homem que não é o seu

\footnotetext{
${ }^{5}$ Seria muito interessante pesquisar o consumo (ou não) de drogas neste meio. Mas esta questão não foi analisada no presente trabalho.

${ }^{6}$ Labirinto é o nome que se dá a determinados ambientes em casas de swing onde há um corredor escuro com uma parede que o divide ao meio. Nesta parede existem buracos de diferentes tamanhos e as pessoas, nuas, se tocam através destes buracos, sem saber exatamente quem está do outro lado.
} 
marido do dia a dia que te conhece, você quer o que? Você quer mostrar que você é gostosa, que você é poderosa... eu acho que isso é do humano, principalmente quando você está em evidência. (Ana).

Outro ponto diretamente ligado à questão da intensidade do prazer advindo da prática do swing é a tentativa de controlar este prazer e moldá-lo a padrões considerados "adequados", não apenas socialmente, mas, especialmente, para os próprios casais. É interessante pensar este aspecto do controle a partir do que Elias e Dunning (1992) afirmam sobre a busca da excitação em sociedades contemporâneas. Segundo os autores, nas sociedades industriais mais avançadas tanto as situações sociais de crise da humanidade quanto as paixões foram sendo submetidas a um controle rigoroso. Explosões incontroladas de forte excitação tornaram-se menos freqüentes e, mesmo nas situações de grandes crises da vida privada dos indivíduos, os fortes sentimentos que daí emergem são escondidos na intimidade do círculo mais íntimo. Nas sociedades contemporâneas a excitação e a emoção "compensadoras" são limitadas por restrições "civilizadoras".

Para os autores, é nas atividades miméticas de lazer que os indivíduos podem compensar a restrição das emotividades na vida ordinária e viver a excitação de forma controlada. Elas se constituirão em um enclave para desencadear, dentro de um quadro social aprovado, um comportamento moderadamente excitado em público. Através destas atividades nossa sociedade satisfaz a necessidade de experimentar em público a explosão de fortes emoções, um tipo de excitação que não coloca em risco a relativa ordem da vida social.

De acordo com Elias e Dunning (1992), grande parte das atividades de lazer desperta emoções que estão relacionadas com outras que as pessoas experimentam em outras esferas - medo, compaixão, ciúme, ou ódio, por exemplo - mas de uma maneira que não é seriamente perigosa como muitas vezes é na vida real. Na esfera mimética, segundo os autores, estas sensações perdem o seu "ferrão", tornam-se prazerosas. Um argumento que surge entre os casais que entrevistei é o de que, quando sentem ciúme, tentam transformá- 
lo em "tesão". Este seria um complemento que tornaria a situação ainda mais excitante, principalmente para os homens. Para um entrevistado:

Eu sentia um ciúme que eu transformava em tesão. Era assim, combustível pro tesão esse ciúme, de saber que ela estava com o cara e imaginar o que eles estavam fazendo, falando, fora do meu controle e eu transformava isso em tesão. Isso era uma coisa que eu gostava muito, que me mantinha assim, excitado. (André)

Elias e Dunning apontam que, nas atividades miméticas, as emoções ou os sentimentos desencadeados por elas - estão relacionadas às emoções que se experimentam em situações de vida real, transpostas e combinadas por uma espécie de prazer. Na prática do swing, a emoção que se busca reviver novamente, em analogia ao que acontece na vida real, parece ser a da sedução. Um dos grandes prazeres mencionados pelos entrevistados é o jogo de conquista entre um homem e uma mulher. Em um depoimento, um entrevistado coloca que a diferença para os homens na prática do swing é:

a novidade, o desconhecido. A oportunidade de causar boa impressão com uma conversa inicial envolvente, com uma abordagem física marcante e com a possibilidade de satisfazer uma mulher que não seja a sua companheira de vida de há tanto tempo. Para as esposas a diferença é a de viver novamente a gostosa sensação de ser conquistada, seduzida e a de ter perto de si um homem determinado a agradar, em satisfazer os desejos e anseios dela para só depois pensar nos dele. (Lucas)

Um dos argumentos de Elias e Dunning é o de que, na sociedade ocidental, a grande excitação inerente ao encontro dos sexos foi limitada a uma forma muito específica, onde a paixão brutal e a excitação constituiriam um grande perigo. A maior excitação possível socialmente reconhecida simbolizada pelo conceito de amor - ao ser ajustada à ordem social, é restrita, 
em princípio, a uma única experiência na vida de cada pessoa. Elias e Dunning chamam atenção para o papel que cumpre a representação do amor em boa parte dos produtos da esfera mimética em nossa sociedade (filmes, livros, comerciais de tv), com o intuito de proporcionar a renovação da excitação específica associada à ligação de um homem e de uma mulher.

Acredito que o swing pode ser interpretado como uma maneira de reafirmar este grande "laço" entre o casal. Os autores argumentam que uma característica comum dos tipos miméticos é a produção de tensões de um tipo específico, o desenvolvimento de uma "tensão-excitação" agradável, uma peça fundamental da satisfação. Na prática da troca de casais, a grande "tensãoexcitação" que está sendo posta em jogo é o risco de ser efetivamente trocado. Este risco, no entanto, é supostamente controlado por uma série de restrições que envolvem a prática e, principalmente, pelo acordo do casal em participar do jogo. É como se experimentassem ali a possibilidade de manterem relações sexuais com outras pessoas, mas de maneira controlada, limitando o risco da separação e também evitando a infidelidade tão temida. A tensão oriunda desta situação gera prazer e o ápice da satisfação acontece na reafirmação do vínculo amoroso entre o casal.

Ao analisar o material sadomasoquista disponível nas sex-shops, Gregori (2004) destaca outro aspecto do erotismo "politicamente correto", a neutralização ou domesticação de conteúdos violentos envolvidos nas práticas sadomasoquistas. Ao se buscar legitimar o sadomasoquismo como uma alternativa erótica aceitável, o aspecto da violência que a ele está associado é substituído por uma conotação de jogo consensual, onde os parceiros brincam com conteúdos ligados a posições de dominação e submissão. A violência é encenada, mas ao mesmo tempo, afastada e neutralizada. Podese pensar que no swing, a simulação / neutralização que entra em jogo não é exatamente da violência, mas sim da situação de traição. Com a proteção das regras que envolvem a prática e por meio do consentimento entre o casal, encena-se uma situação de traição, que é domesticada pelo acordo de participar do jogo e pela possibilidade de sair dele quando se deixa uma casa de swing ou quando a festa termina. 
Desta maneira, pode-se dizer que a prática do swing permite que se experimente uma agradável excitação, o prazer sexual com outras pessoas, que pode ser desfrutado sem ter como conseqüência as suas perigosas implicações sociais e individuais: o fim do casamento monogâmico ou a separação do casal.

\section{O CORNO E A PUTA}

Gostaria de refletir sobre dois "personagens" que constituem o universo sexual e de gênero brasileiros, a puta e o corno, e que parecem rondar de maneira particular o meio swinger.

Parker (1991) destaca que no Brasil, homem e mulher se definem não somente um em relação ao outro, mas também com referência a uma série de figuras adicionais que incorporam uma complexa ordem de possibilidades, positivas ou negativas, de machos e fêmeas. Para o autor, a representação do homem é construída não apenas em oposição à mulher, mas também em sua relação com figuras como o machão, o corno, a bicha ou viado. Da mesma forma, a mulher precisaria ser compreendida não apenas em oposição ao homem, mas através de figuras como a virgem, a piranha ou a sapatão.

Parker entende que a figura do homem brasileiro incorpora valores tradicionalmente relacionados ao papel de macho, entre eles força e poder, virilidade e potência sexual. O homem, como machão ou pai, deve ser compreendido em contraste com as figuras do viado e do corno. $\mathrm{Na}$ concepção do autor, o viado e o corno representariam tudo aquilo que o verdadeiro homem não pode ser.

Para Parker, a traição por parte da mulher fere e ao mesmo tempo transforma o homem, constituindo um ataque frontal à sua identidade masculina. A possibilidade de que a própria mulher possa traí-lo a qualquer hora seria um dos fantasmas do homem brasileiro e, neste sentido, ela representa uma ameaça, um perigo constante.

É interessante notar como a figura do corno entre os praticantes de swing apresenta uma imagem ambígua que envolve prazer e perigo. Por um 
lado, a prática do swing aparece para os homens como uma tentativa de controlar essa eterna ameaça feminina, a de ser traído a qualquer momento. No discurso de um entrevistado a traição por parte da mulher aparece não como mera uma possibilidade, mas como uma verdade incontestável.

Tem um outro ingrediente. O medo de ser corno oficial, corno sem saber é grande e leva alguns homens a fazer a mulher, assim, desfrutar de... todo mundo sabe que um dia a mulher vai trair. Essa é a máxima. Um dia ela trai, nem que seja daqui a 10 anos, ela vai te trair. Porque dificilmente uma pessoa consegue se sentir atraída pela mesma pessoa a vida inteira. Chega uma hora, daqui a algum tempo que vai chegar uma pessoa que vai te dizer alguma coisa, além dele. $\mathrm{E}$ os homens têm medo disso, entendeu? De você estar sozinha numa situação e chegar alguém no seu ouvido e te levar. Então para não te dar o motivo de fazer, o cara te dá essa oportunidade de fazer com a anuência dele. (André).

Desta forma, ao dar a chance à mulher de ter relações sexuais com outros homens com a sua concordância, procura afastar o medo de ser "corneado". O perigo, neste caso, reside não no ato em si - a relação de sua mulher com outro homem - mas no seu caráter oculto, escondido, incontrolável. $\mathrm{O}$ homem aparece como uma vítima em potencial.

Por outro lado, permitir que a sua mulher se relacione sexualmente com outros homens, gera uma espécie de fascínio. Pelo menos cinco dos meus entrevistados relataram que este é o seu maior prazer na prática do swing. Dois entrevistados disseram que tal prazer é maior inclusive do que relacionar-se sexualmente com duas mulheres ao mesmo tempo, o que, para muitos, é a grande fantasia sexual masculina. Segundo um entrevistado "a grande maioria das vezes o tesão maior é do homem vendo a mulher transar, isso ai é... A maioria das vezes é o homem que gosta de ver a sua mulher transar" (André).

Este prazer parece ser despertado justamente pelo perigo, pela ameaça de "perder" a mulher, uma espécie de desafio constante à própria potência e 
virilidade. Ao ver a mulher tendo prazer com outro homem se sente desafiado a melhorar ainda mais a sua própria performance sexual, para provar que é merecedor de tê-la como sua esposa.

Eu tenho muita segurança no meu desempenho como homem com ela, na nossa relação afetiva e eu tenho a certeza absoluta de que tudo que alguém faça com ela eu posso fazer melhor. É até um desafio para mim. Cada vez que ela transa com um cara eu procuro, quando chego em casa, fazer melhor. (André)

Estabelece-se, assim, uma competição entre homens, entre machos, que procuram provar que são os melhores. Pode-se ver, nesta competição, reflexos de um possível desejo sexual pelo outro homem. No entanto, no discurso dos pesquisados não aparece esta questão.

O prazer derivado de ver a sua mulher com outro homem pode ser pensado como uma prova de poder masculino, através da exibição da performance sexual e corporal de sua esposa. $O$ fato de ela ser considerada uma mulher atraente e sensual aumentaria o seu poder, uma vez que ele é o “escolhido", ele é o "dono" do objeto de desejo de todos. É o que aparece no depoimento de uma entrevistada: "porque eu acho que o tesão dele era assim, 'ab tem alguém comendo a minha mulher, ela é gostosa, mas ela é minha'. Eu acho que a fantasia dele passava por aí. Acho que no fundo ele tinha uma fantasia meio de ser corno" (Ana).

O prazer gerado seria uma espécie de combinação de poder e perigo. O depoimento de uma entrevistada exemplifica bem esta idéia: "ele falou que quando o homem chega perto de mim, dá um frio na barriga dele, uma sensação de ciúme e que isso reaviva o nosso relacionamento, que ele sente uma coisa forte por mim nesses momentos" (Júlia).

Aparece ainda no discurso dos entrevistados, um outro lado da fantasia, o de "cantar" e se relacionar sexualmente com uma mulher casada, sem que esta atitude se traduza em brigas ou desentendimentos entre homens. A mesma entrevistada descreve a fantasia de seu parceiro no swing: 


\begin{abstract}
Mexer com a mulher do outro, entendeu, sem que haja algum problema, algum mal estar. E já percebi que ele gosta sempre das mulheres que estão acompanhadas com os seus maridos ou namorados né, geralmente ele não gosta de mexer com mulher sozinha. Ele gosta sempre de mulher que está casada, está acompanhada. (Júlia)
\end{abstract}

A prática do swing seria uma forma de evitar e se precaver contra a desmoralização e emasculação simbólica de que nos fala Parker (1991). Os praticantes de swing apresentam, dessa maneira, uma relação ambígua com a figura do corno. Ao mesmo tempo que surge como uma acusação potencial a todos os homens adeptos da troca de casais, já que permitem que suas mulheres se relacionem com outros homens, também encontram prazer e desafio no "perigo" de serem trocados.

Nas entrevistas ouvi relatos sobre a presença de casais "armados" em casas de swing, homens que pagam prostitutas para acompanhá-los em dias onde a entrada é restrita a casais. Tais casais adquirem uma imagem negativa entre os praticantes, sua presença é considerada altamente indesejável e os adeptos do swing procuram maneiras, seja na roupa ou no comportamento, de identificar os "armadores" e afastá-los. A idéia é que a troca com estes casais não seria uma troca justa, uma vez que o homem só paga a prostituta para acompanhá-lo, mas não para se relacionar sexualmente com outros homens. A imagem que se tem destes homens pode ser associada à do malandro, aquele que vai a uma casa para "comer a mulher dos outros", mesmo que não possua nada para oferecer em troca (DaMatta, 1983). A tentativa de afastar estes casais também pode ser vista como uma busca de diferenciação por parte das esposas, que não querem ser confundidas com a prostituta.

A "puta" aparece no depoimento das entrevistadas ao falarem da acusação e do preconceito da sociedade em relação à sua prática. O depoimento de uma entrevistada reforça esta idéia: "as pessoas olham para você como se você fosse um E.T., como se você fosse uma promiscua, como se você fosse uma... sei lá, uma puta que dá para todo mundo" (Ana). 
Pode-se verificar, no entanto, a presença de outro imaginário, desta vez cercado de positividade, relacionado ao potencial erótico que a figura da puta parece despertar entre as mulheres. Para Parker (1991), a confirmação da masculinidade e da virilidade dos seus parceiros e ao mesmo tempo a negação do controle dos homens sobre o seu comportamento sexual, tem como efeito a produção de certo encantamento com esta personagem. A puta representaria uma mulher sexualmente mais livre para viver seus desejos e fantasias sexuais, uma mulher que gosta de sexo e procura valorizar e exibir o seu corpo. Esta representação se expressa de maneira mais explícita no depoimento das entrevistadas, em "brincadeiras", ou na própria maneira de se vestir.

No blog de um casal ${ }^{7}$ encontrei uma frase que me ajudou a refletir sobre as roupas e os comportamentos de algumas mulheres nas casas de swing: "toda mulher sadia tem a fantasia de ser uma puta?". O uso de vestidos curtos, de minissaias, saltos alto e o costume de algumas mulheres de fazer strip-tease em um pequeno palco (chamado de "queijo" e especialmente localizado para este fim em casas de swing), pode ser um indicativo da sedução que a figura da prostituta exerce sobre aqueles indivíduos.

Muitas atitudes das mulheres praticantes de swing se relacionam com as apontadas por Gaspar (1988) em seu estudo sobre as garotas de programa. $\mathrm{Na}$ descrição do comportamento das mulheres nas boates para arranjar um programa, a autora menciona a dança como forma de sedução e erotização do corpo, a apresentação sobre o "queijo", o strip-tease feminino, as relações sexuais entre mulheres, o uso de salto alto. Todos estes comportamentos também podem ser vistos nas casas de swing. As roupas que as mulheres vestem procuram valorizar as mesmas partes que as garotas de programa estudadas por Gaspar buscavam com o uso da lycra: as pernas, as nádegas e os seios. Algumas praticantes de swing contam que, em algumas noites, tiveram relações sexuais com oito ou dez homens diferentes.

A prática do swing aparece como uma espécie de desafio ao imaginário que cerca estas duas personagens liminares: o corno e a puta. Um homem que sabe e permite que sua mulher se relacione sexualmente com outros homens

${ }^{7}$ http:// casalbambamepedrita.blig.ig.com.br/. Último acesso em 13 de janeiro de 2010.

Temáticas, Campinas, 20(40): PG-PG, ago./dez. 2012 
pode certamente ser acusado de corno. Uma mulher que se veste em trajes curtos, justos e sensuais, que se exibe e faz strip-tease em um palco e se relaciona sexualmente com muitos homens em uma noite é a perfeita "piranha" descrita por Parker (1991).

O universo controlado de uma casa de swing permite que certos aspectos apontados por Parker sobre a sexualidade tanto feminina (o controle e a limitação), quanto masculina (cujo potencial sexual precisa ser constantemente construído e sustentado contra a constante ameaça de desvio que a figura do corno representaria), sejam subvertidos. O medo de "ser corneado" não deixa de aparecer. A prática do swing funcionaria como uma espécie de atenuante desta ameaça, ao mesmo tempo em que produziria efeitos eróticos "inesperados". De maneira semelhante, a figura da puta não deixa de ser indesejada, como a presença de uma profissional, pela troca desequilibrada que produz, ou como fator de acusação, mas reaparece de outra forma nas roupas, nas práticas e nas fantasias sexuais dos adeptos de swing.

\section{“SWING SOCIAL CLUBE"}
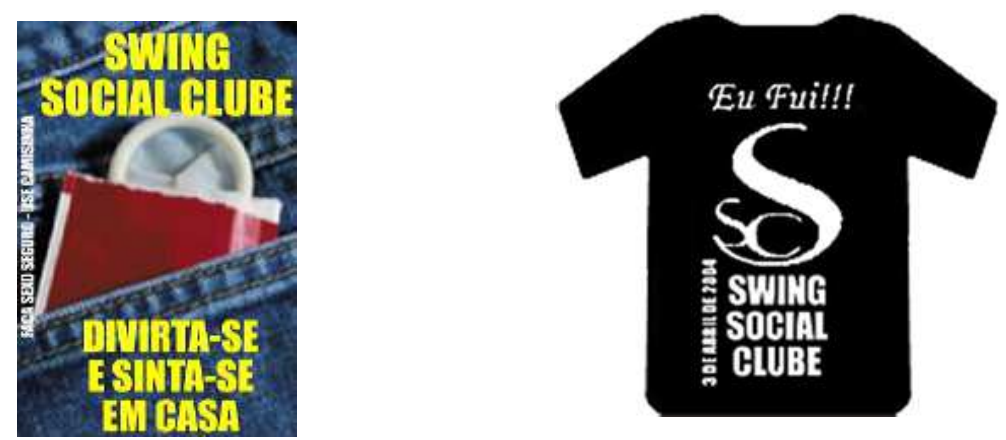

Estas duas imagens foram tiradas de um blog $^{8}$. As festas produzidas e organizadas por este casal recebiam o nome de "Swing Social Clube" e uma das atividades que aconteciam na noite eram os "Encontros de mulheres

${ }^{8}$ www.fantasiasdecasados.com.br. Último acesso em 13 de janeiro de 2010.

Temáticas, Campinas, 20(40): PG-PG, ago./dez. 2012 
liberais". A idéia de "sinta-se em casa" expressa um aspecto importante observado entre os casais pesquisados, a criação de uma rede social, incluindo laços de amizade para além do ambiente das casas ou festas de swing.

Nas conversas nos dias de encontro, ouvi relatos de viagens em conjunto, incluindo a presença dos filhos de alguns casais, menções a saídas para outros programas, onde o sexo não estava incluído (como casas de dança, cinema ou jantares, por exemplo). Alguns casais passaram o ano novo de 2003 para 2004 juntos, tendo viajado para o mesmo lugar, um indício da estreita amizade que criaram. No depoimento de um casal destaca-se:

Cláudio: na realidade você acaba conhecendo pessoas e vira amizade e a pessoa acaba dando o endereço e sem a gente precisar pedir... a gente tem amigos que a gente freqüenta a casa já há um tempão.

Carolina: é, conhece a família inteira... conhece a minha família e eu conheço a deles.

Cláudio: conhece filhos e a gente também conhece filhos e quando está com os filhos ninguém... amigo, pessoa normal entendeu? ninguém fala em swing.

A amizade que se estabelece entre os casais é apontada como de um tipo especial, que envolve ou envolveu relações sexuais. Esta possibilidade aumentaria o grau de intimidade e a cumplicidade da relação de amizade. No depoimento de outro casal entrevistado aparece esta questão:

Daniela: a gente conheceu pessoas maravilhosas...

Diogo: pode-se dizer que a gente ficou apaixonado assim, por alguns casais...

Daniela: tem casais assim que a gente fica apaixonado mesmo...

Diogo: porque a gente entranha tanto na vida deles, eles entranham tanto na nossa vida, né, a gente tem uma liberdade tão grande, que passa até a não fazer mais sexo, mas tem uma intimidade... 
Daniela: uma cumplicidade, uma intimidade assim muito boa.

Outro ponto interessante que aparece neste depoimento é o de que o desenvolvimento do vínculo de amizade pode contribuir, dependendo do casal, para diminuir o interesse sexual. Tornar-se amigo, tornar-se íntimo, seria um fator que "inibiria o tesão". Outro entrevistado também se refere a esta questão: "o que acontecia, se reunia todo mundo, ia pra uma suruba e a gente acabava não se envolvendo, porque? Primeiro que não dá pra transar com amigo, tem gente que consegue, eu não consigo. Fiquei amigo demais, sabe? não rola e ela também não" (André).

O desenvolvimento de relações afetivas de intimidade, que se transformam em amizade, aparece como um ganho inesperado da entrada para o swing. Em seus depoimentos, os casais invariavelmente mencionam os amigos conquistados como um dos principais aspectos positivos que o swing trouxe para suas vidas. A imagem que tinham antes de aderirem à prática está relacionada a encontros eróticos fortuitos, a aventuras sexuais episódicas, mas em seus discursos o estabelecimento de laços contínuos e o conhecimento de pessoas com interesses em comum é extremamente valorizado.

Eu encontrei no swing uma coisa que eu não estava esperando que é a amizade das pessoas, na minha idéia era uma coisa muito... era só sexo, aquela coisa de fantasias eróticas. Para mim isso ia chegar em uma época em que "ah, não tem nada a ver, não quero mais isso", e no entanto você cria um grupo de amigos. O mais legal de tudo realmente foi o grupo de amigos que a gente fez. (Carolina)

Outra entrevistada disse: "no swing eu fiz um casal de amigos verdadeiros, que eu considero pra caramba que são eles dois, freqüentam, conhecem a minha mãe, entendeu?" (Ana).

Apesar da amizade poder ser vista como um problema para alguns casais que buscam o sexo casual em casas de swing, ela aparece como uma das motivações para se freqüentar o meio. Ir a uma casa de swing representa 
outras possibilidades além do sexo: a dança, a música, a conversa com os amigos. Este lado social se apresenta não apenas em uma casa de swing, mas em outros ambientes freqüentados por casais adeptos da prática.

Carolina: a gente era muito voltado para a casa, para a família, então a gente estava meio que esquecido. A gente ia para o trabalho, casa... e agora não, agora a gente pensa na gente, tá um dia de sol, "ah, vamos para a praia, vamos encontrar com o pessoal", a gente tem disposição para sair de noite, porque sabe que vai encontrar as pessoas, que vai conversar.

Cláudio: e nem sempre a gente quando procura a praia ou clube não vai com intenção de... se acontecer aconteceu. E se acontecer é com quem interessa.

Carolina: a gente acaba indo mais por divertimento.

Cláudio: a gente vai hoje mais por divertimento do que para procurar sexo.

Percebe-se, então, que a troca de casais, ao menos entre os pesquisados, envolve importantes elementos além de uma troca exclusivamente sexual. Com o surgimento do aspecto "social", a troca passa a ser não apenas de casais, mas entre casais. Sem perder de vista o objetivo erótico dos que praticam o swing, aparece, também, como um ganho secundário, a amizade conquistada no meio.

\section{CONSIDERAÇÕES FINAIS}

Neste trabalho procurei realizar uma reflexão sobre o prazer entre os praticantes de swing. Quatro dimensões essenciais surgem vinculadas à sua concepção de prazer: a fantasia, a transgressão, a intensidade e o controle.

Começando com uma imagem de transgressão, com um comportamento sexual inusitado que "perturba a ordem", vemos que a prática 
de swing não pode ser entendida apenas por um lado contestador. A liberdade sexual não parece tão simples de ser alcançada e os casais praticantes de swing tentam garanti-la buscando sua adequação a padrões aceitáveis e regrados.

O swing, para alguns, é apenas uma das fantasias em uma série de muitas outras. Com o passar do tempo, para certos casais (não todos), o swing deixa de ser um estímulo, não é mais tão excitante, e novas fantasias são criadas e buscadas. A lógica do desejo, fantasia, consumo, frustração e novos desejos, presentes na sociedade de consumo aparece aqui associada à esfera da sexualidade.

Ao contrário dos libertinos, os swingers não estão se propondo a uma experiência radical de prazer, buscam sim vivenciar certos prazeres dentro de uma determinada ordem que sirva como controle e limite.

Neste sentido, é interessante observar como alguns casais desenvolvem vínculos de amizade no meio, que aparecem como ganhos e prazeres inesperados advindos da prática. Este vínculo adquire uma importância no universo pesquisado e tem conseqüências diversas para a manutenção ou transformação das relações sexuais entre casais.

Tendo no corpo a sua principal fonte de prazer, os casais procuram satisfazer as suas fantasias sexuais transgredindo, dentro de um limite determinado, certas convenções sociais sobre sexo e casamento. No atual hedonismo moderno concretizar fantasias não leva à satisfação, gerando apenas prazeres momentâneos, frustração, novos desejos e novas fantasias a serem realizadas. O limite deste jogo aparentemente não tem fim, mas no caso do swing, uma prática a dois, ele parece se encontrar nos limites de uma relação afetiva. No entanto, por meio da separação entre sexo e amor e sob o domínio do consentimento, o swing pode acabar reafirmando as convenções existentes.

\title{
REFERÊNCIAS BIBLIOGRÁFICAS
}

\author{
BUTLER, Judith. Problemas de gênero: feminismo e subversão da identidade. \\ Rio de Janeiro: Civilização Brasileira, 2003.
}


CAMPBELL, C. The romantic ethic and the spirit of modern consumerism. Oxford: Blackwell, 1995.

DAMATTA, R. Carnavais, Malandros e Heróis: para uma sociologia do dilema brasileiro. Rio de Janeiro: Zahar, 1983.

DUARTE, L. F. D. A sexualidade nas ciências sociais: leitura crítica das convenções. In: PISCITELLI, A. \& GREGORI, M. F. \& CARRARA, S. (orgs.). Sexualidade e saberes: convenções e fronteiras. Rio de Janeiro: Garamond, p. 39-80, 2004.

ELIAS, N. \& DUNNING, E. A busca da excitação. Lisboa: Difel, 1992.

FOUCAULT, M. História da sexualidade: a vontade de saber. São Paulo: Graal, 2005.

GASPAR, M. D. Garotas de programa. Rio de Janeiro: Zahar, 1988.

GREGORI, M. F. Prazer e perigo: notas sobre feminismo, sex-shops e S/M. In: PISCITELLI, A. \& GREGORI, M. F. \& CARRARA, S. (orgs.). Sexualidade e saberes: convenções e fronteiras. Rio de Janeiro: Garamond, p. 235-255, 2004.

MORAES, E. R. Sade. A Felicidade Libertina. Rio de Janeiro: Imago, 1994.

PARKER, R. G. Corpos, prazeres e paixões. São Paulo: Best Seller, 1991.

RUBIN, Gayle. Thinking sex: notes for a radical theory of the politics of sexuality. In: VANCE, C. (Org.). Pleasure and danger: exploring female sexuality. New York: Routledge, p. 267-319, 1984.

SIMMEL, G. As grandes cidades e a vida do espírito (1903). Mana, Vol. 11, n. 2, 2005, p. 577-591.

VARGAS, E. V. Os Corpos Intensivos: sobre o estatuto social do consumo de drogas legais e ilegais. In: DUARTE, L. F. D. \& ODINA, F. L. Doença, Sofrimento, Perturbação: perspectivas etnográficas. Rio de Janeiro: Editora Fiocruz, 1998, p. 121-136. 
VON DER WEID, O. Masculino e Feminino na prática do swing. Sexualidade, Saúde e Sociedade Revista Latino-Americana, América do Norte, 0, dez. 2009. Disponível em: http://www.e-publicacoes.uerj.br/ index.php/SexualidadSaludySociedad/article/view/43. Acesso em: 13 Jan. 2010.

Temáticas, Campinas, 20(40): PG-PG, ago./dez. 2012 